\title{
The Effect of Natural Disasters on Housing Prices: An Examination of the Fourmile Canyon Fire
}

\author{
By
}

Kathy Kiel and Victor Matheson

August 2015

\section{COLLEGE OF THE HOLY CROSS, DEPARTMENT OF ECONOMICS FACULTY RESEARCH SERIES, PAPER NO. 15-03*}

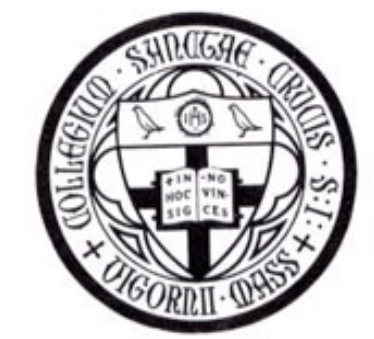

Department of Economics College of the Holy Cross Box 45A

Worcester, Massachusetts 01610

(508) 793-3362 (phone)

(508) 793-3708 (fax)

http://www.holycross.edu/departments/economics/website

*All papers in the Holy Cross Working Paper Series should be considered draft versions subject to future revision. Comments and suggestions are welcome. 


\title{
The Effect of Natural Disasters on Housing Prices: An Examination of the Fourmile Canyon Fire
}

\author{
By \\ Katherine A. Kiel ${ }^{\dagger}$ \\ College of the Holy Cross \\ and \\ Victor A. Matheson ${ }^{\dagger+}$ \\ College of the Holy Cross \\ Draft: August 2015
}

\begin{abstract}
In September 2010, the Fourmile-Lefthand Canyon forest fire burned 6,181 acres, destroyed 169 homes, and caused \$217 million in property damages making it by far the most expensive fire in Colorado history at the time. This paper examines how the fire affected housing prices in vulnerable neighboring areas that were not directly impacted by the fire, controlling for the property's level of risk. This damaging fire may have increased home owners' perceptions about the risk of living in forested areas subject to wildfires to a significant degree adding to the total direct economic losses from the fire. Utilizing a unique fire risk data set and a difference-indifference approach, we test whether buyers of houses in areas with different risk levels prior to the fire adjust expectations differently. We find buyers in the highest risk area are most likely to change their perceptions in response to a fire with houses in these areas experiencing a statistically significant $21.9 \%$ decline in sale price.
\end{abstract}

JEL Classification Codes: Q54, R11, R21

Keywords: disasters, forest fires, housing, climate change

${ }^{\dagger}$ Katherine A. Kiel, Department of Economics \& Accounting, Box 17A, College of the Holy Cross, Worcester, MA 01610-2395, 508-793-2743 (phone), 508-793-3708 (fax), kkiel@holycross.edu

"Victor A. Matheson, Department of Economics \& Accounting, Box 157A, College of the Holy Cross, Worcester, MA 01610-2395, 508-793-2649 (phone), 508-793-3708 (fax), vmatheso@holycross.edu 


\section{Introduction}

In September 2010, the Fourmile Canyon forest fire burned 6,181 acres, destroyed 169 homes, and caused \$217 million in property damages in the mountains directly west of Boulder, Colorado. At the time, the Fourmile fire was the most damaging in Colorado history with insured losses five times larger than the next most expensive recorded forest fire in the state's history and over twice as large as the losses from the next ten most damaging Colorado fires combined. (See Table 1). It also burned more houses than any previous Colorado wildfire, and its location just five miles west of downtown Boulder, a major urban center, served to focus significant local and national media attention on the event.

The damage caused by the Fourmile Canyon fire was a magnitude greater than anything seen in Colorado previously, but within two years, its destruction was exceeded by the High Park fire in Larimer Country west of Fort Collins and the Waldo Canyon fire in the outskirts of Colorado Springs. In June 2012, the High Park fire burned 87,250 acres (the second largest fire in Colorado history), destroyed 256 homes (exceeding the record set by the Fourmile fire), and caused \$113.7 million in insured damages. With the High Park fire not yet fully contained, the Waldo Canyon fire erupted west of Colorado Springs. It eventually consumed 18,247 acres, destroyed 347 homes, and caused $\$ 453.7$ million in insured property damages, breaking the records set by the Fourmile Canyon fire. The Colorado Springs area was hit again in 2013 when the Black Forest fire consumed more than 14,000 acres and destroyed 489 homes worth $\$ 420.5$ million, eclipsing the Waldo Canyon fire in terms of homes destroyed.

While wildfires are nothing new to Colorado, it is evident that the severity of damages associated with forest fires has risen dramatically in just the past few years. In the thirty years between 1976 and 2006, 387 homes across the state were lost to forest fires, while over 1,326 were destroyed in just the three years between 2010 and 2013. At least three root causes can 
serve to explain the increase in fire damages. First, fire suppression techniques and forest management over the past century have led to an increase in damaging fires across the country. Second, climate change is contributing to weather and forest conditions that favor fires. According to the National Research Council (2011), the mountains and foothills west of the major population centers in Colorado can expect a 656\% percent "increase in burned areas... for a $1.8^{\circ} \mathrm{F}$ increase in global average temperatures relative to the median area burned during 1950 2003.” Finally, Colorado has experienced a large increase in the population living in areas at high risk for wildfires. In 2010, 1.1 million Coloradans lived is a so-called "red-zone,” an increase of 29 percent since 1990 (Kodas and Hubbard, 2012).

While the damage directly caused by wildfires is clear, this paper seeks to examine the effect of wildfires on home prices in at-risk but unaffected areas. While natural disaster risk is clearly incorporated in the price of any housing unit, a fire of the magnitude of the Fourmile, Black Forest, High Park, or Waldo Canyon fires may serve to change public perceptions of risk in a measurable way. By estimating the impact on house values for areas that were not directly impacted, we can more fully understand the economic effect of these fires. In addition, our work allows us to consider whether owners of homes that are exposed to different risk levels change perceptions in different ways after a fire takes place.

\section{Literature Review}

The existing literature on the economic effect of natural disasters on housing prices has often addressed the issue of risk. Bin and Polasky (2004), Chivers and Flores (2002), and Atreya, Ferreira, and Kriesel (2013) all examine the effect of major floods on housing prices in flood plains, i.e. areas at high risk for flood damages. All three papers note that local housing values in 
flood plains are observed to fall immediately after flooding events, but the decrease in prices tends to be short-lived.

Donovan, Champ, and Butry (2007) examine home prices in the wilderness-urban interface in El Paso County, Colorado, the location of the Waldo Canyon fire, both before and after the Colorado Springs Fire Department rated the wildfire risk of 35,000 local housing parcels in 2000 in an effort to increase awareness of risk. Prior to the on-line publication of the wildfire risk data, fire risk was positively correlated to housing prices (presumably due to the amenity aspects of solitude and the proximity of natural beauty) while after the publication of the risk assessment the "benefits" of owning a home prone to fire risk was significantly reduced. It is worth noting that Donovan, Champ, and Butry (2007) specifically mention the potential for large fires to affect housing values but do not test specifically for this possibility. To wit,

There is one other factor to consider when evaluating the effectiveness of this educational campaign. In June 2002, the Hayman fire burned 138,000 acres mostly on the Pike National Forest (17,000 acres were on the Pikes Peak Ranger District); it destroyed 132 homes and came within 20 miles of Colorado Springs. Although homeowners in the study area were not directly threatened by the Hayman fire, some of the observed effect on the housing market may be attributable to this fire. We cannot determine how much of the observed effect on the housing market was due to the educational campaign and how much was due to the Hayman fire. (Donovan, Champ, and Butry, 2007, pg. 232)

Stetler, Venn, and Calkin (2010) study 18,785 housing sales in Montana from June 1996 to January 2007. Their model includes neighborhood characteristics such as distance to the nearest golf course, and environmental variables such as distance to major lakes and rivers. Their wildfire variables included distance to the nearest wildfire perimeter in the previous seven years, and if the area burned could be seen from the home. They find home prices in the northwest portion of the state less than $5 \mathrm{~km}$ and between $5 \mathrm{~km}$ and $10 \mathrm{~km}$ from a wildfire burn area were $13.7 \%(\$ 33,232)$ and $7.6 \%(\$ 18,924)$ lower, respectively, than equivalent homes at 
least $20 \mathrm{~km}$ from a fire. Homes with views of burn areas decreased in value even further. In this work the authors control for distance from a fire, but not explicitly for risk. It may be that distance and risk are correlated, but their results do not provide direct evidence of impact of a change in risk.

Loomis, Mueller, and Gonzalez-Caban (2009) examine prices of homes within 1.75 miles of a series of three fires that took place between 1989 and 2003 in Southern California near the Angeles National Forest. They find that home prices respond to repeated fires by falling significantly. While housing prices fell only 9.7\% after one fire, they dropped an additional 22.7\% after the second wildfire. Their model, however, only controls for distance to the center of each wildfire; there is no control for the level of risk to which each house is exposed.

Loomis (2004) examines 134 properties sales before and over 300 sales after the Buffalo Creek wildfire in 1996 that burned 12,000 acres and destroyed 10 homes near the community of Pine, Colorado. The study finds a 15\% decrease in home values in the neighboring community after the fire, a result that the author suggests is due to a revised attitude of homebuyers regarding the perceived wildfire risk of the area or a loss in forest amenities in the community. While house characteristics are included in the regression, there is no measure of distance from the fire, nor is there any control for the level of risk each house is subject to. The results do suggest that buyers adjust their perceptions after a wildfire.

Xu and van Kooten (2013) also identify a decrease in property values associated with forest fires. Most directly related to the research here is the fact that they find more significant reductions in property values associated with larger fires. Thus, if their results are applicable in Colorado, a fire the magnitude of the Fourmile fire should have the most significant effects on property values. 


\section{Data and Model}

Data for 9,630 single family housing sales that occurred between January 2009 and April 2012 in Boulder County, where the Fourmile Canyon fire occurred, were purchased from the Warren Group. This time period represents roughly 18 months before and after the Fourmile Canyon fire, and the data end two months prior to the even larger High Park and Waldo Canyon fires. The data include sales date and price, housing structural characteristics, and address data for GIS geocoding and mapping. Because relevant variables regarding the fire risk associated with each house's location was not available for other areas, the sample was limited to housing sales in Boulder County. Neighborhood characteristics were collected via the Census website and were applied to each house based on their census tracts (see Table 2 for descriptive statistics). Observations were omitted if the house listed zero bedrooms or bathrooms, reported living space equal to zero, was situated in a location with a fire risk assessed as zero, had a clearly identifiable typographical error, or could be identified as a non-market or non- armslength transaction where the sales price would not reflect the actual value of the house. After cleaning, 9,403 housing sales remained. See Figure 1 for a map of house sales locations in Boulder County.

In order to include the fire risk for each house as a characteristic of the house, we utilized a rating system from the Boulder county GIS website that assessed the risk of damage that would occur due to a forest fire (given that one occurred) to different areas of Boulder County. The fire risk in various areas was rated as "very high,” "high,” “medium,” or “low.” According the county office,

"This data represents a classification of the expected relative wildfire severity under the assumption of the occurrence of a moderate to high severity fire weather event within 
Boulder County. This assessment is based on the physical attributes of slope, aspect and vegetation fuel type, and is based on the USDA Forest Service's fire behavior model BEHAVE and Van Wegner's crown fire spread equations.” (Boulder County Land Use, 2000)

Using this information, we were able to merge the risk rating to the homes based on the overlaying of information in the GIS program. See Figure 2 for a map of the levels of risk along with house sales locations. Figure 2 shows the eastern half of the county, an area of plains and the most populous region, is generally designated as low risk while areas in the mountainous and generally heavily forested western half of the county carries higher risk ratings.

The hedonic house pricing model assumes that the sales price of a house can be broken down into the price of each observed characteristic of the house (see Rosen, 1974 and Freeman, 1993). When environmental factors such as fire risk are included in the estimated model, the estimated coefficient reveals the price that individuals must be compensated in order to take on the increased risk.

The previous papers using hedonic pricing to value fire risk either examine fires that did not occur during the time period of the data or utilize a simple dummy variable to identify house sales that occur after a fire has taken place. If a study only examines fires that occurred prior to the time period of the data, such as Stetler, Venn, and Calkin (2010), it is clear that the study cannot be used to measure the change in risk perception that can occur from a major disaster. If a study examines current fires but only utilizes a simply dummy variable for measuring the time period after the fire, such as Loomis, Mueller, and Gonzalez-Caban (2009) and Loomis (2004), then any results can be affected by general trends or volatility in housing prices or changes in the mix of the riskiness of housing sold. 
In order to correct for these potential problems, we utilize hedonic pricing incorporating a difference-in-differences technique (see Wooldridge, 2009 for a discussion). The model to be estimated is

$$
\text { lnPrice }_{i}=\beta_{0}+\sum_{k=1}^{K} \beta_{k} x_{i k}+\sum_{m=K+1}^{M} \beta_{m} y_{i m}+\delta_{1} \text { Risk }_{i}+\delta_{2} \text { After }_{i}+\delta_{3} \text { Risk } * \text { After }+\varepsilon
$$

where $x_{i k}$ is a vector of house specific characteristics including age of the house (age) as well as age squared (age_sq), the number of bedrooms and bathrooms, lot acreage (lot_area), and the square footage of the home’s living area (bldg_livin). These are standard variables commonly included in hedonic analyses of housing. $y_{i m}$ is a vector of neighborhood characteristics based on the census tract in which the house is located including the racial composition of the population (pct_white, pct_black, pct_hispanic) and the percentage of population below poverty level (below_poverty). Dummy variables for the city in which each house was located were also included.

Two models are estimated with a different measure of risk included in each model. e level of risk for each house of the severity of fire is categorized by

Model (1) groups together all houses with a risk above "low” so that a variable (risk_adj) is generated and set equal to one if the house is determined to reside with a very high, high, or medium risk fire zone and zero otherwise. As can be seen in Table 2, roughly 4\% of all single family home sales in our data set involved houses located in an area with a risk level above low. In model (2), we create a dummy variable for each risk category (very_high_risk, high_risk, medium_risk, and low_risk) separately with the "low" category serving as the omitted variable in the regression. We have no prior expectation of sign of the coefficients on risk variables as homes in high risk areas may also be in "high amenity” areas. 
The difference-in-difference approach is commonly used when data come from a natural experiment caused by an exogenous event. The event then leads to a control group that is not impacted by the event, and a treatment group that may be impacted. Since the two groups are not randomly chosen in a natural experiment, systematic differences in the groups need to be controlled for. By using data from before and after the event, we can consider four different groups: the control group before and after the event, and the treatment group before and after the event. Then the estimate of the impact of the event on house prices is the difference of the difference in the average prices between the two groups before and after the event.

The variable "after_dummy" takes on a value of one for house sales that took place in the time period after the Fourmile fire, and zero otherwise, and distinguishes between sales before and after the event. We have no prior expectation of this sign, but since the trend in house prices in the time period after the fire was generally positive, it is likely that this coefficient will be positive. Finally, interaction terms between the after dummy variable and the various measures of risk are created. For Model (1), the estimated coefficient on “risk_adj_eff” (equal to “risk_adj”*”after_dummy”) is then an estimate of the difference in the difference of average prices, and will allow us to test whether people purchasing homes after the fire viewed risk differently than those who purchased before the fire. For Model (2), “very_high_risk_eff”, "high_eff”, and “medium_eff” are the respective interaction variables for the various risk measures.

\section{Results}

The average sales prices for Model (1) in areas of the combined high risk and low risk both before and after the fire are included in Table 3. Notice that the house sales prices in the 
high-risk area were greater than those in the low risk area prior to the fire. This suggests that homes in those areas have more natural amenities such as views, which leads to higher sales prices. After the fire, however, homes in the riskier areas sold at a lower prices after the fire while housing prices were increasing in low risk areas. This leads us to expect that buyers in riskier areas changed the values placed on environmental amenities relative to the value placed on risk after the fire took place. Of course, these numbers do not control for the characteristics of the homes or their neighborhoods, which is why regression analysis is called for. Table 4 includes information on how many sales occurred in each risk category and when the sales occurred.

The regression results are in Table 5. Column 1 reports the coefficients for model (1) with one combined risk category for all houses in areas above low-risk. Column 2 reports the coefficients for model (3) including three separate risk categories. In both models the housing characteristics take on the expected signs, and all but the area of the lot are statistically significant. The neighborhood characteristics from the census track data are also of the expected signs and are statistically significant. ${ }^{1}$ The city variables, with the unincorporated areas as the excluded area, are also as expected.

For model (1) the coefficient on the after indicator variable (after_dummy) suggests that house prices were higher (by roughly 1.85\%) after the fire took place. This, however, does not mean that the fire itself increased prices. By looking at the risk variable (risk_adj), we can see that housing in riskier areas sold for approximately 5.6\% less than housing in non-risky areas, all else held constant. However, this variable is not statistically significant. The interaction term

\footnotetext{
${ }^{1}$ The regressions were also estimated replacing the census tract variables and city dummy variables with separate dummy variables for each census tract. The regression results were similar. Results are available from the authors upon request.
} 
between risk and after the fire is also negative, which means that houses in risky areas sold for even less (by an additional 5.0\%) after the fire. Although not statistically significant, this does suggest that perceptions of risk did change after the fire took place.

It is possible that the formulation of the risk variable which combines all high levels of risk is masking some of the variation. In column 2 we present results with the risk variable in all three categories, with low risk being the excluded group. Again, the house characteristics are of the expected sign and all except the area of the lot are statistically significant. The census tract variables are also of the correct sign and statistical significance, as are the city variables. As in Model (1), the coefficient on the variable which indicates if the sale took place after the fire is positive and statistically significant; house prices in Boulder County were higher after the fire.

Houses in the very high risk areas show a statistically significant impact on sales prices, with the effect being positive so that these houses sell at a premium of $17.5 \%$ over houses in low risk areas. Houses in the medium risk area sell at a discount relative to the low risk area, a reduction in price of $7.9 \%$. Being in a high risk area also reduces values (by $8.7 \%$ ) although this figure is not statistically significant, so it would be reasonable to conclude that being in a high risk area does not seem to have an impact on price, once other aspects of the house and the neighborhood are controlled for. The explanation for the different effects of risk on housing prices likely involved the tradeoff between the amenity values of housing in risky area and the transportation costs associated with traveling from relatively remote locations in the mountains to the employment centers in on the plains. Very high risk areas are disproportionately located closer to the plains providing these homes with both superior views and easy access to the area's population centers. High and medium risk areas tend to be both more remote and potentially less scenic. 
The most interesting aspect of the regression results is the effect of the fire on housing prices in risky areas. After the fire, the houses in very high risk areas experience a reduction in their sales price of $21.9 \%$ compared to houses sold in low risk areas after the fire, and that effect is statistically significant. The combined effect of living in a high risk area is that prior to fire these homes sold at a statistically significant $17.5 \%$ premium compared with homes in low risk areas while after the fire, these homes sold at a $4.4 \%$ discount (17.5\% minus $21.9 \%)$. One reasonable interpretation of this result is that the fire did indeed impact buyers' perceptions of risk, especially in the highest risk areas.

When estimating the total economic impact of the fire on the values of houses in Boulder County as a result of changes in risk perception, there are a few ways to proceed. One way to calculate loss is to estimate changes in assessed values. The assessed value for residential singlefamily homes in Boulder County in 2014 was \$2.637 billion (Boulder County Assessor’s Office, 2015). If the percentage of homes in risky areas in the county is similar to the percentage in our data set (3.9\%), and those houses fell in value by $5.0 \%$ after the fire (as suggested by the coefficient on "risk_adj_eff” in Model (1), then the total decrease in assessed value due to changes in perceptions would be $\$ 5.142$ million.

Since the coefficient for risk in Model (1) after the wildfire is not statistically significant, another option is to consider only those houses that are classified as located in areas that are very high risk as in Model (2). If the percentage of homes in Boulder County that are in very high risk areas (0.36\%), and the average price premium for houses in very high risk areas (17.5\%) prior to the fire is the same as in our data set, then the $21.9 \%$ fall in house values in those areas after the fire represents a total decrease in assessed value of $\$ 2.45$ million. 
In Boulder County, comparing the averaged assessed value to the median market value suggests that market value is roughly 12.65 times assessed value. Taking the losses to assessed value and adjusting them to market values yields losses of \$65 million and \$31 million. When compared to the insured losses of $\$ 217$ million from the fire, the losses to homeowners in Boulder County whose homes were not destroyed or damaged are fairly substantial.

\section{Conclusions}

While the damage directly caused by wildfires is clear, this paper seeks to examine the effect of wildfires on home prices in at-risk but unaffected areas. While natural disaster risk is clearly incorporated in the price of any housing unit, a fire of the magnitude of the Fourmile, High Park, or Waldo Canyon fires may serve to change public perceptions of risk in a measurable way.

Our regression results suggest that buyers' perceptions do change in response to a wildfire. It appears that the buyers that are most impacted are those in the very high risk areas. It is possible that prior to the fire, the value those buyers placed on amenities such as views and isolation was greater than the value they placed on safety. After seeing what a fire can do, it seems that those weights reversed to the extent that the sales price of the homes in those areas

fell. It does not appear that perceptions of risk changed for buyers in the high and medium risk areas in Boulder County.

Overall, the dollar impact to house prices in at-risk but unaffected areas is substantial. It is important to consider these numbers when calculating the potential costs of fires when conducting cost-benefit analyses. 


\section{References}

Atreya, Ajita, Susana Ferreira, and Warren Kriesel. 2013. Forgetting the Flood? An Analysis of the Flood Risk Discount over Time. Land Economics 89:4, 577-596.

Bin, Okmyung, and Stephan Polasky. 2004. Effects of Flood Hazards on Property Values:

Evidence before and after Hurricane Floyd. Land Economics 80:4, 490-500.

Boulder County Assessor’s Office. 2015. Total Assessed Valuation for Boulder County, http://www.bouldercounty.org/dept/assessor/pages/abstracts.aspx, accessed July 2, 2015.

Boulder County Land Use. 2000. Boulder County Overall Wildfire Hazard Assessment. http://www.bouldercounty.org/gov/data/gisdldata/wildfire\%20hazard\%202000.txt, accessed July 2, 2015.

Chivers, James, and Nicholas E. Flores. 2002. Market Failure in Information: The National Flood Insurance Program. Land Economics, 78:4, 515-21.

Donovan, G.H., Champ, P.A., Butry, D.T., 2007. Wildfire risk and housing prices: a case study from Colorado Springs. Land Economics, 83:2, 217-233.

Freeman, A Myrick. 1993. The Measurement of Environmental and Resource Values; Theory and Methods. Resources for the Future, Washington D.C.

Kodas, Michael and Burt Hubbard. 2012. Policies put more Coloradan at risk. Rocky Mountain Public Broadcasting Service. http://inewsnetwork.org/2012/06/27/policies-put-morecoloradans-at-risk/, posted June 27, 2012, accessed July 2, 2015.

Loomis, John B. 2004. Do nearby forest fires cause a reduction in residential property values? Journal of Forest Economics 10:3, 149-157.

Loomis, John B., Mueller, Julie and Gonzalez-Caban, Armando, 2009. Do Repeated Wildfires Change Homebuyers’ Demand for Homes in High-Risk Areas? A Hedonic Analysis of 
the Short and Long-Term Effects of Repeated Wildfires on House Prices in Southern California. Journal of Real Estate Finance and Economics, 38:2, 155-172.

National Research Council. 2011. Climate Stabilization Targets: Emissions, Concentrations, and Impacts over Decades to Millennia. Washington, DC: The National Academies Press.

Rosen, Sherwin. 1974. Hedonic prices and implicit markets: product differentiation in pure competition. Journal of Political Economy, 82:1, 34-55.

Stetler, K.M., Venn, T.J., Calkin, D.E. 2010. The effects of wildfire and environmental amenities on property values in northwest Montana. Ecological Economics, 69:11, 2233-2243.

Wooldridge, Jeffrey M. 2009. Introductory Econometrics: A Modern Approach. Fourth Edition. South-Western Cengage Learning, Mason, Ohio.

Xu, Zhen and G. Cornelis van Kooten. 2013. Living with Wildfire: The Impact of Historic Fires on Property Values in Kelowna, BC. Economics \& Policy Analysis Research Group, Department of Economics, University of Victoria, Working Paper 2013-05. 
Table 1

$\begin{array}{llrrrc}\text { Fire } & \text { County } & \text { Year } & \text { Houses } & \text { Million \$ } & \text { Acreage (rank) } \\ \text { Black Forest } & \text { El Paso } & 2013 & 489 & \$ 420.5(2) & 14,280(15) \\ \text { Waldo Canyon } & \text { El Paso } & 2012 & 347 & \$ 453.7(1) & 18,247(12) \\ \text { High Park } & \text { Larimer } & 2012 & 256 & \$ 113.7(4) & 87,250(3) \\ \text { Fourmile } & \text { Boulder } & \mathbf{2 0 1 0} & \mathbf{1 6 9} & \mathbf{\$ 2 1 7 . 0 ( 3 )} & \mathbf{6 , 1 8 1}(\mathbf{2 5}) \\ \text { Hayman } & \text { El Paso } & 2002 & 133 & \$ 38.7(5) & 137,760(1) \\ \text { Iron Mountain } & \text { Fremont } & 2002 & 100 & \$ 7.5(10) & 4,439(29) \\ \text { Missionary Ridge } & \text { La Plata } & 2002 & 56 & \$ 17.7(7) & 71,739(4) \\ \text { Hi-Meadow } & \text { Park } & 2000 & 51 & \$ 18.5(6) & 10,800(20) \\ \text { Black Tiger Gulch } & \text { Boulder } & 1989 & 44 & \$ 10.0(9) & 1,778(38) \\ \text { Coal Seam } & \text { Garfield } & 2002 & 29 & \$ 6.4(11) & 12,209(17) \\ \text { Lower North Fork } & \text { Jefferson } & 2012 & 27 & \$ 11.0(8) & 3,790(31) \\ \text { Fremont County includes Cañon City } & & & \\ \text { Garfield County includes Glenwood Springs } & & & \\ \text { La Plata County includes Durango } & & & \\ \text { Park County includes Bailey (but the fire may have been primarily in Jefferson) }\end{array}$

Insurance Costs/

\section{Damages (rank)}

http://www.denverpost.com/breakingnews/ci_23626934/final-count-homes-destroyed-blackforest-fire-is

http://www.rmiia.org/catastrophes_and_statistics/Wildfire.asp

http://www.huffingtonpost.com/2013/07/10/black-forest-fire_n_3572931.html 
Figure 1

\section{Cities and Housing Sales in Boulder County, Colorado}

\section{Legend \\ FourMileCanyonFirePerimeter - Cities in Boulder County House Sales in Boulder County Boulder County Blank}

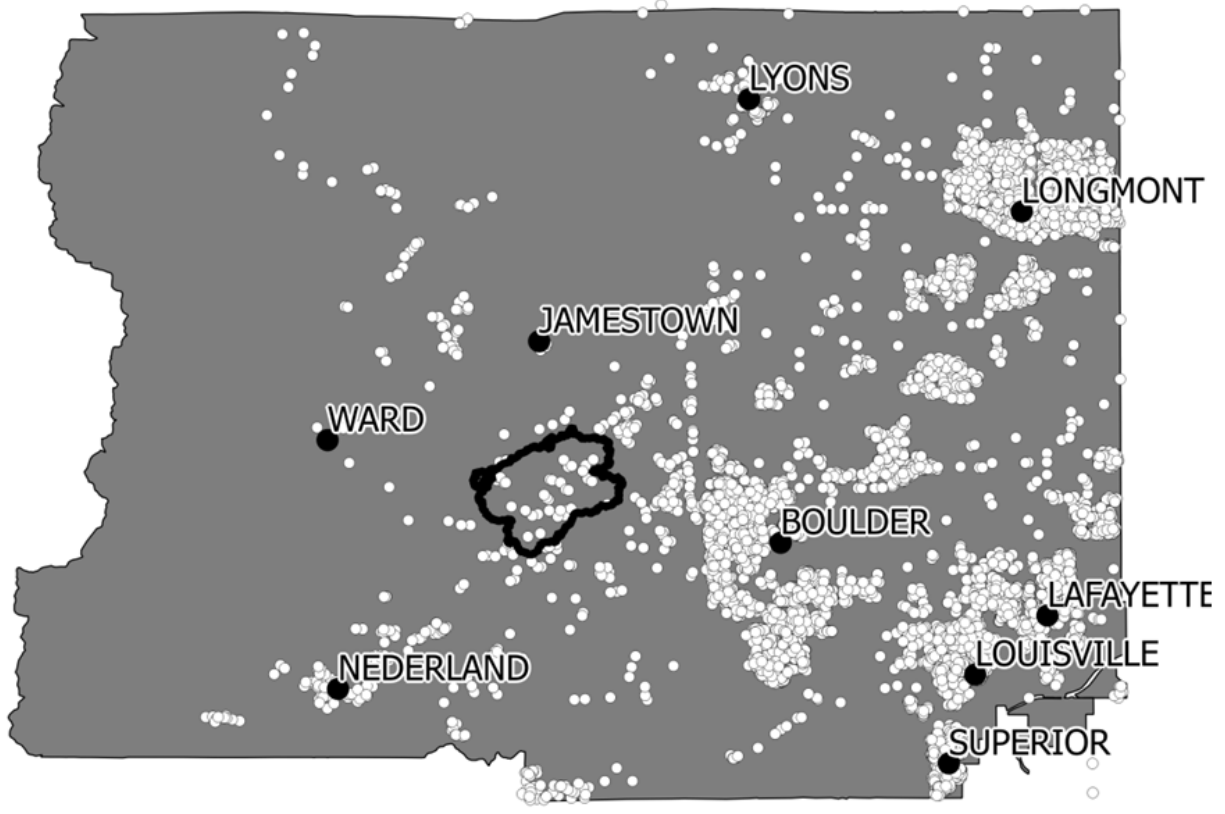

Scale:

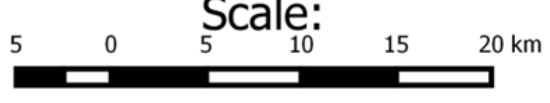


Figure 2

\section{Wildfire Risk and Housing Sales in Boulder County, Colorado}

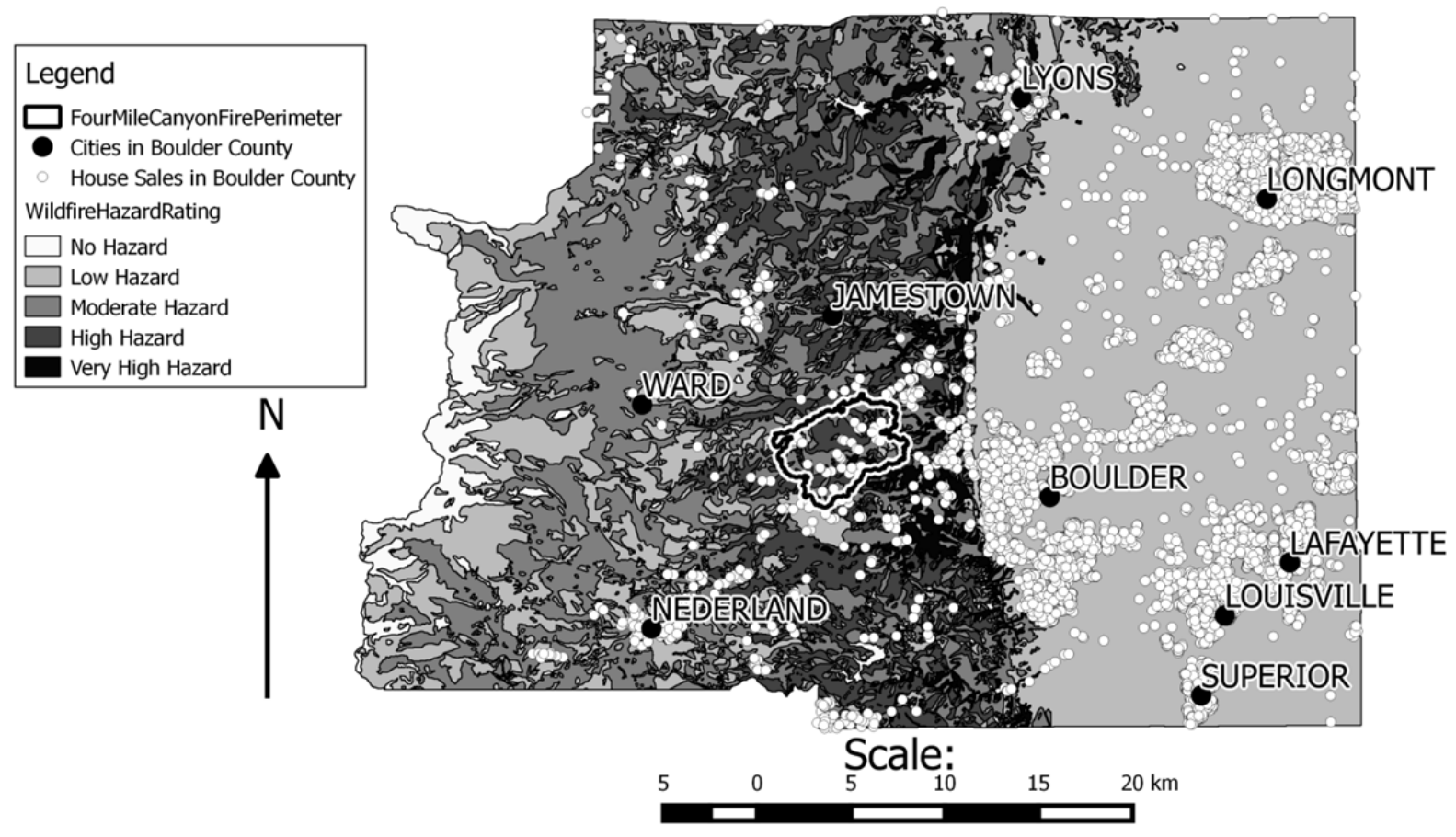


Table 2: Descriptive Statistics

\begin{tabular}{|c|c|c|c|c|c|}
\hline Variable & Description & Mean & St. Dev. & Min. & Max. \\
\hline Inprice & Log of Price of house & 12.711 & .58710 & 8.987 & 16.783 \\
\hline lot_area & Property’s lot area & 113800 & 4232400 & 26 & 332000000 \\
\hline bldg_livin & Building’s area & 2193.7 & 1083.0 & 396 & 12534 \\
\hline Age & Age of house & 30.310 & 23.095 & 0 & 137 \\
\hline age_sq & Age of house squared & 1452.0 & 2320.7 & 0 & 18769 \\
\hline bathrooms & \# of full bathrooms in unit & 2.7293 & 1.0936 & 1 & 9 \\
\hline bedrooms & \# of bedrooms in unit & 3.3324 & .93416 & 1 & 9 \\
\hline pct_white & $\begin{array}{l}\text { Percent of White homeowners } \\
\text { in census tract }\end{array}$ & 89.918 & 6.5508 & 65.4 & 100 \\
\hline pct_black & $\begin{array}{l}\text { Percent of Black homeowners in } \\
\text { census tract }\end{array}$ & 1.3763 & 1.3161 & 0 & 5.2 \\
\hline pct_hispanic & $\begin{array}{c}\text { Percent of Hispanic } \\
\text { homeowners in census tract }\end{array}$ & 12.634 & 12.031 & 1.4 & 59.2 \\
\hline below_poverty & $\begin{array}{l}\text { Percent of homeowners below } \\
\text { poverty line in census tract }\end{array}$ & 6.0895 & 6.7678 & 0 & 29.6 \\
\hline after_dummy & $\begin{array}{c}=1 \text { if sale took place after the } \\
\text { wildfire }\end{array}$ & .46017 & .49844 & 0 & 1 \\
\hline Boulder & $=1$ if House located in Boulder & 23056 & .42122 & 0 & 1 \\
\hline Erie & $=1$ if located in Erie & .04850 & 21482 & 0 & 1 \\
\hline Lafayette & $=1$ if located in Lafayette & .09805 & .29740 & 0 & 1 \\
\hline Longmont & $=1$ if located in Longmont & .32883 & 46981 & 0 & 1 \\
\hline Louisville & $=1$ if located in Louisville & .0739126 & 26164 & 0 & 1 \\
\hline Lyons & $=1$ if located in Lyons & .00798 & .08896 & 0 & 1 \\
\hline Nederland & $=1$ if located in Nederland & .00510 & .07127 & 0 & 1 \\
\hline Superior & $=1$ if located in Superior & .04977 & .21748 & 0 & 1 \\
\hline very_high_risk & $\begin{array}{c}=1 \text { if located in very high risk } \\
\text { fire hazard area }\end{array}$ & .00362 & .06003 & 0 & 1 \\
\hline high_risk & $\begin{array}{c}=1 \text { if located in high risk fire } \\
\text { hazard area }\end{array}$ & .01032 & .10105 & 0 & 1 \\
\hline medium_risk & $\begin{array}{c}=1 \text { if located in medium risk fire } \\
\text { hazard area }\end{array}$ & .02584 & .158867 & 0 & 1 \\
\hline very_high_eff & Very_high_risk * after_dummy & .00181 & .04248 & 0 & 1 \\
\hline high_eff & high_risk * after_dummy & .00596 & .07695 & 0 & 1 \\
\hline medium_eff & medium_risk * after_dummy & .01244 & .11086 & 0 & 1 \\
\hline risk_adj & $\begin{array}{c}=1 \text { if house in very high, high, } \\
\text { or medium risk area }\end{array}$ & .03977 & .19544 & 0 & 1 \\
\hline risk_adj_eff & Risk_adj*after_dummy & .02021 & .14071 & 0 & 1 \\
\hline
\end{tabular}


Table 3

\begin{tabular}{|c|c|c|}
\hline Average Sales Price & Before the Fire & After the Fire \\
\hline High Risk & $\$ 367,527$ & $\$ 348,045$ \\
\hline Low Risk & $\$ 325,340$ & $\$ 336,271$ \\
\hline
\end{tabular}


Table 4

Distribution of Sales Dates

\begin{tabular}{|l|l|l|}
\hline \# sales & Before fire & After fire \\
\hline Low Risk & 4891 & 4134 \\
\hline Medium Risk & 126 & 117 \\
\hline High Risk & 41 & 56 \\
\hline Very High Risk & 17 & 17 \\
\hline
\end{tabular}


Table 5: Regression Results

\begin{tabular}{|c|c|c|}
\hline VARIABLES & $\begin{array}{c}(1) \\
\text { Ln price }\end{array}$ & $\begin{array}{c}(2) \\
\text { Ln price }\end{array}$ \\
\hline lot_area & $\begin{array}{l}4.59 \mathrm{e}-10 \\
\quad(6.14 \mathrm{e}-10)\end{array}$ & $\begin{array}{c}4.59 \mathrm{e}-10 \\
(6.16 \mathrm{e}-10)\end{array}$ \\
\hline bldg_livin & $\begin{array}{c}0.000249 * * * \\
(7.95 \mathrm{e}-06)\end{array}$ & $\begin{array}{c}0.000248 * * * \\
(7.95 \mathrm{e}-06)\end{array}$ \\
\hline age & $\begin{array}{c}-0.00817 * * * \\
(0.0006)\end{array}$ & $\begin{array}{c}-0.00818 * * * \\
(0.0006)\end{array}$ \\
\hline age_sq & $\begin{array}{c}8.08 \mathrm{e}-05 * * * \\
(6.05 \mathrm{e}-06)\end{array}$ & $\begin{array}{c}8.08 \mathrm{e}-05 * * * \\
(6.05 \mathrm{e}-06)\end{array}$ \\
\hline bathrooms & $\begin{array}{c}0.0468 * * * \\
(0.0057)\end{array}$ & $\begin{array}{c}0.0471 * * * \\
(0.0057)\end{array}$ \\
\hline bedrooms & $\begin{array}{c}0.0203 * * * \\
(0.0057) \\
\end{array}$ & $\begin{array}{c}0.0206 * * * \\
(0.0057)\end{array}$ \\
\hline pct_white & $\begin{array}{c}0.0064 * * * \\
(0.0010)\end{array}$ & $\begin{array}{c}0.0064 * * * \\
(0.0010)\end{array}$ \\
\hline pct_black & $\begin{array}{c}-0.0112 * * * \\
(0.0030)\end{array}$ & $\begin{array}{c}-0.0111^{* * * *} \\
(0.0030)\end{array}$ \\
\hline pct_hispanic & $\begin{array}{c}-0.0048 * * * \\
(0.0005)\end{array}$ & $\begin{array}{c}-0.0049 * * * \\
(0.0005)\end{array}$ \\
\hline below_poverty & $\begin{array}{c}-0.0020 * * \\
(0.0008)\end{array}$ & $\begin{array}{c}-0.0020 * * \\
(0.0008)\end{array}$ \\
\hline Boulder & $\begin{array}{c}0.329 * * * \\
(0.0155)\end{array}$ & $\begin{array}{c}0.329 * * * \\
(0.0155)\end{array}$ \\
\hline Erie & $\begin{array}{c}-0.378^{* * * *} \\
(0.0186)\end{array}$ & $\begin{array}{c}-0.377 * * * \\
(0.0186)\end{array}$ \\
\hline Lafayette & $\begin{array}{c}-0.222 * * * \\
(0.0169) \\
\end{array}$ & $\begin{array}{c}-0.222 * * * \\
(0.0169) \\
\end{array}$ \\
\hline Longmont & $\begin{array}{c}-0.369 * * * \\
(0.0162)\end{array}$ & $\begin{array}{c}-0.369 * * * \\
(0.0162) \\
\end{array}$ \\
\hline Louisville & $\begin{array}{c}-0.0392 * * \\
(0.0156) \\
\end{array}$ & $\begin{array}{c}-0.0391 * * \\
(0.0157) \\
\end{array}$ \\
\hline Lyons & $\begin{array}{c}-0.162 * * * \\
(0.0357) \\
\end{array}$ & $\begin{array}{c}-0.160^{* * * *} \\
(0.0358)\end{array}$ \\
\hline Nederland & $\begin{array}{c}-0.258 * * * \\
(0.0524)\end{array}$ & $\begin{array}{c}-0.241^{* * *} \\
(0.0558)\end{array}$ \\
\hline Superior & $\begin{array}{c}-0.160 * * * \\
(0.0190)\end{array}$ & $\begin{array}{c}-0.160 * * * \\
(0.0190)\end{array}$ \\
\hline after_dummy & $\begin{array}{c}0.0185 * * * \\
(0.0065)\end{array}$ & $\begin{array}{c}0.0186 * * * \\
(0.0065)\end{array}$ \\
\hline very_high_risk & & $\begin{array}{c}0.175^{* * * *} \\
(0.0663)\end{array}$ \\
\hline high_risk & & -0.0870 \\
\hline
\end{tabular}




\begin{tabular}{|c|c|c|}
\hline & & $(0.0553)$ \\
\hline \multirow[t]{2}{*}{ medium_risk } & & $-0.0790 *$ \\
\hline & & $(0.0478)$ \\
\hline \multirow[t]{2}{*}{ very_high_eff } & & $-0.219 * *$ \\
\hline & & $(0.1060)$ \\
\hline \multirow[t]{2}{*}{ high_eff } & & 0.0228 \\
\hline & & $(0.0807)$ \\
\hline \multirow[t]{2}{*}{ medium_eff } & & -0.0572 \\
\hline & & $(0.0674)$ \\
\hline \multirow[t]{2}{*}{ risk_adj } & -0.0559 & \\
\hline & $(0.0366)$ & \\
\hline \multirow[t]{2}{*}{ risk_adj_eff } & -0.0502 & \\
\hline & $(0.0501)$ & \\
\hline \multirow[t]{2}{*}{ Constant } & $11.70^{* * * *}$ & $11.70 * * *$ \\
\hline & $(0.101)$ & $(0.101)$ \\
\hline Observations & 9,403 & 9,403 \\
\hline R-squared & 0.723 & 0.724 \\
\hline
\end{tabular}

Robust standard errors in parentheses *** $\mathrm{p}<0.01,{ }^{* *} \mathrm{p}<0.05,{ }^{*} \mathrm{p}<0.1$ 